\title{
Contribution of Renal and Non-Renal Clearance on Increased Total Clearance of Adalimumab in Glomerular Disease
}

\author{
Brittney V. Roberts, BS', Isidro Susano', Debbie S. Gipson, MD, MSPH ${ }^{2}$, \\ Howard Trachtman, MD $^{3}$, and Melanie S. Joy, PharmD, PhD'
}

\begin{abstract}
The contribution of renal and non-renal clearance toward targeted concentrations and/or effects of therapeutic proteins in nephrotic patients are unknown. This study dissected the contribution of clearance pathways to adalimumab elimination in patients with focal segmental glomerulosclerosis (FSGS). Urine was collected from seven patients treated with adalimumab. Renal clearance $\left(\mathrm{Cl}_{R}\right)$ was measured and non-renal clearance $\left(\mathrm{Cl}_{N R}\right)$ was calculated as the difference between total clearance and $\mathrm{Cl}_{R}$. Differences in cumulative amount in urine, $\mathrm{Cl}_{R}$, and $\mathrm{Cl}_{N R}$ between study weeks I and I6 and relationships between proteinuria (protein:creatinine ratio $\left(U_{p} / c\right)$ ), and $\mathrm{Cl}_{R}$ and $\mathrm{Cl}_{N R}$ were evaluated. $U_{P}$ to $13 \%$ of the adalimumab dose was lost in urine. $\mathrm{Cl}_{\mathrm{NR}}$ contributed more than $\mathrm{Cl}_{R}$ to enhanced total clearance. There was a nonlinear relationship between $U p / c$ and $C l_{R}\left(R^{2} 0.7059\right)$; an increase in $\mathrm{Cl}_{R}$ beginning at $\mathrm{Up}_{\mathrm{p}} / \mathrm{c}$ of $\mathrm{I} 2 \mathrm{mg} / \mathrm{mg}$ [slope I.755, (C.I. -7.825 to II.34)]. There was a linear relationship between $\mathrm{Up}_{\mathrm{p}} / \mathrm{c}$ and $\mathrm{Cl}_{\mathrm{NR}}\left(\mathrm{R}^{2} 0.5039\right)$; for every one unit increase in $\mathrm{Up} / \mathrm{c}, \mathrm{Cl}_{\mathrm{NR}}$ would increase by $3.5 \mathrm{~mL} / \mathrm{hr}(P=0.0 \mathrm{I})$. Both $\mathrm{Cl}_{\mathrm{R}}$ and $\mathrm{Cl}_{\mathrm{NR}}$ contribute to enhanced total clearance of adalimumab in glomerular disease secondary to FSGS. Additional research is needed to identify mechanisms for the increased $\mathrm{Cl}_{\mathrm{NR}}$ pathways.
\end{abstract}

\section{Keywords}

glomerulonephritis, pharmacokinetics, renal clearance, non-renal clearance, focal segmental glomerulosclerosis

The use of therapeutic proteins for the treatment of primary glomerular diseases has been increasing. Based on results of the RAVE study, rituximab, an antibody against CD20 on B cells, was FDA approved for the treatment of kidney manifestations of anti-neutrophil cytoplasmic antibody (ANCA) associated small vessel vasculitis in 2011. ${ }^{1}$ Several additional studies have reported on the use of rituximab in patients with other glomerular diseases including lupus nephritis, membranous nephropathy, and focal segmental glomerulosclerosis (FSGS). ${ }^{2-7}$ Adalimumab, a human monoclonal antibody to TNF- $\alpha$, is effective in treating inflammatory diseases including rheumatoid arthritis, ankylosing spondylitis, Crohn's, and psoriasis. ${ }^{8,9}$ Several publications have reported the use of infliximab, a therapeutic antibody protein to TNF- $\alpha$, for the treatment of lupus nephritis. ${ }^{10,11}$

A major limitation to prescribing therapeutic proteins in patients with glomerular disease is the lack of knowledge of how the presence and/or severity of the nephrotic syndrome influences the clearance of large (molecular weight $145 \mathrm{kD}$ ) IgG-based proteins. This is particularly important given the expense of these agents relative to small molecule therapeutics and the knowledge that $\mathrm{IgG}$, while not considered to be renally eliminated, can be eliminated through the kidneys of proteinuric patients. ${ }^{12}$ Additionally, hypercatabolism of IgG has been reported in animal models of lupus and rheumatoid arthritis. $^{13,14}$

FSGS is one of the most common causes of primary glomerular disease. It progresses to end stage kidney disease in the majority of patients who have persistent proteinuria despite treatment with steroids and other immunosuppressive medications. Patients with FSGS have elevated circulating levels of tumor necrosis factor- $\alpha(\mathrm{TNF}-\alpha) .{ }^{15}$ An animal study reported upregulation of kidney TNF- $\alpha$ expression prior to the appearance of proteinuria in Buff/Mna rats that spontaneously

\footnotetext{
'Skaggs School of Pharmacy and Pharmaceutical Sciences, University of Colorado, Aurora, Colorado

${ }^{2}$ Department of Pediatrics, School of Medicine, University of Michigan, Ann Arbor, Michigan

${ }^{3}$ Division of Nephrology, NYU Langone Medical Center, New York, New York

Submitted for publication 23 March 2013; accepted 29 May 2013.

Corresponding Author:

Melanie S. Joy, Department of Pharmaceutical Sciences, Skaggs School of Pharmacy and Pharmaceutical Sciences, Anschutz Medical Campus, University of Colorado, Mail Stop C238, Room V20-4108, 12850 E. Montview Blvd, Aurora, CO 80045.

E-mail: melanie.joy@ucdenver.edu
} 
developed FSGS. ${ }^{16}$ We previously reported a Phase I study that demonstrated safety and tolerability of adalimumab in pediatric and young adult patients with resistant FSGS. ${ }^{17}$ We evaluated the pharmacokinetics (PK) of adalimumab in serum and found adalimumab clearance values during single-dose and multi-dose studies that were two- to fivefold higher, respectively, than previously reported values in patients with rheumatoid arthritis. ${ }^{17}$ This finding led to the current investigation.

The current study evaluated the contribution of renal versus non-renal clearance to the increased total clearance of adalimumab in patients with FSGS. Other objectives were to evaluate the difference in renal and non-renal clearance values for adalimumab after a single- and multiple- dose, and to evaluate the relationship between urinary protein:creatinine excretion $(\mathrm{Up} / \mathrm{c})$ versus renal and non-renal clearance of adalimumab.

\section{Methods}

Ten patients with a diagnosis of FSGS were treated with adalimumab as part of a phase I study. ${ }^{17,18}$ This study received Institutional Review Board approval and was conducted in accordance with the Declaration of Helsinki. Patients received adalimumab $24 \mathrm{mg} / \mathrm{m}^{2}$ (maximum dose: $40 \mathrm{mg}$ ) subcutaneously every 14 days for 16 weeks. PK variables were assessed after the first dose of adalimumab at week 0 and repeated at steady state, following the week 16 dose, as previously reported. ${ }^{17}$ Urine was collected at the following time intervals: $-0-2,2-12$, 12-24, 24-36, and 36-42 hours - during the two PK studies.

Urine samples from seven of the ten patients were available for measurement of adalimumab concentrations by an immunoassay (Q-ADA, Sanquin Blood Supply's Monoclonal Therapeutics Laboratory, Netherlands).

\section{Pharmacokinetics}

Adalimumab serum PK variables, including total clearance and area under the plasma concentration time curve
(AUC), were available from our previous analyses. ${ }^{17}$ The cumulative amount of adalimumab in the urine was calculated by multiplying the concentration by collection volumes for each respective urine collection interval and then summing the values over all of the intervals for each subject during the PK assessment. Adalimumab renal clearance was calculated as the cumulative amount excreted in the urine over the 42 hours collection period divided by the AUC. Since total clearance is the sum of renal clearance and non-renal clearance, adalimumab nonrenal clearance was calculated as the total clearance minus the renal clearance.

\section{Statistics}

The difference in cumulative amount of adalimumab excreted in the urine and the difference in renal clearance values and non-renal clearance values at week 0 and week 16 , respectively, were compared using a paired $t$-test. The relationships between $\mathrm{Up} / \mathrm{c}$ in the first morning specimen versus renal and non-renal clearance values of adalimumab, respectively, were evaluated by regression.

\section{Results}

The demographics of the seven FSGS patients, for whom urine samples were available, demonstrated an age of $18 \pm 10$ years, $\mathrm{Up} / \mathrm{c}$ of $12.1 \pm 5.6 \mathrm{mg} / \mathrm{mg}$ at baseline (week 0) and $7.9 \pm 7.7 \mathrm{mg} / \mathrm{mg}$ at week 16 , estimated glomerular filtration rate (eGFR) of $110 \pm 55 \mathrm{~mL} / \mathrm{min}$ at baseline (week 0) and $111 \pm 45 \mathrm{~mL} / \mathrm{min}$ at week 16 (Table 1). Thus, at the start of the study all of the patients had normal kidney function and nephrotic-range proteinuria. All but two patients had a reduction in the $\mathrm{Up} / \mathrm{c}$ at week 16. Additional data on the FSGS patients enrolled in the Phase 1 adalimumab study were previously reported. ${ }^{17}$

Urines from the week 0 (single dose) collections were available for analysis of adalimumab concentrations for six out of seven patients. All seven patients had residual urine samples for assessment of adalimumab concentrations at week 16 . The cumulative amount of adalimumab in the urine ranged from $<1 \%$ of the dose to up to

Table I. Patient Demographics

\begin{tabular}{|c|c|c|c|c|c|c|}
\hline Patient ID & Race & $\begin{array}{c}\text { Age } \\
\text { (years) }\end{array}$ & $\begin{array}{l}\text { Urine protein to } \\
\text { creatinine excretion at } \\
\text { week } 0(\mathrm{mg} / \mathrm{mg})\end{array}$ & $\begin{array}{l}\text { Urine protein to } \\
\text { creatinine excretion at } \\
\text { week } 16(\mathrm{mg} / \mathrm{mg})\end{array}$ & $\begin{array}{l}\text { Glomerular filtration } \\
\text { rate at week } 0 \\
(\mathrm{~mL} / \mathrm{min})\end{array}$ & $\begin{array}{l}\text { Glomerular filtration } \\
\text { rate at week } 16 \\
(\mathrm{~mL} / \mathrm{min})\end{array}$ \\
\hline I & White & 13 & 9.2 & 14.0 & 174 & 152 \\
\hline 2 & Hispanic & 15 & 20.0 & 22.0 & 204 & 152 \\
\hline 3 & White & 27 & II.I & 6.7 & 71 & 74 \\
\hline 4 & White & 6 & 15.0 & 6.9 & 89 & 79 \\
\hline 5 & White & 20 & 9.1 & 4.4 & 88 & 66 \\
\hline 6 & Multi & 9 & 17.0 & 0.6 & 62 & 173 \\
\hline 7 & White & 36 & 3.6 & 0.6 & 85 & 84 \\
\hline Mean \pm St Dev & & $18 \pm 10$ & $12.1 \pm 5.6$ & $7.9 \pm 7.7$ & $110 \pm 55$ & $\mathrm{III} \pm 45$ \\
\hline
\end{tabular}


$13 \%$ of the dose. (Table 2 ) When comparing the amount of adalimumab in the urine from week 0 to week 16 , two patients had an increase, while the remaining four had consistent amounts $(P=0.30)$. While the renal contribution to total clearance was substantially less than the nonrenal contribution, it was $>1 \%$ in 5 of the $13(38 \%)$ doses evaluated, with the highest value reaching $13 \%$. Renal clearance of adalimumab in patients without kidney disease is expected to be zero.

The renal clearance of adalimumab at week 0 and week 16 demonstrated an increase in three patients and a stable amount in the other three patients $(P=0.15)$ (Figure 1a) The mean \pm standard deviation renal clearance was $0.7 \pm 1.0 \mathrm{~mL} / \mathrm{hr}$ and $1.6 \pm 2.5 \mathrm{~mL} / \mathrm{hr}$, at week 0 and 16, respectively. The difference in non-renal clearance of adalimumab at week 0 and week 16 demonstrated an increase in one patient, a reduction in two patients, and no change in three patients $(P=0.70)$ (Figure 1b). The mean \pm standard deviation nonrenal clearance was $34.5 \pm 15.5 \mathrm{~mL} / \mathrm{hr}$ and $36.2 \pm 45.9 \mathrm{~mL} /$ $\mathrm{hr}$, at week 0 and 16 , respectively.

The relationships between proteinuria and renal clearance of adalimumab demonstrated a direct relationship by nonlinear regression analysis (slope 1.755 (C.I. -7.825 to 11.34 ), EC50 25.46 (C.I. -113.0 to 163.9), $\mathrm{R}^{2}$ 0.7059). An increase in $\mathrm{Cl}_{\mathrm{R}}$ was demonstrated beginning at a $\mathrm{Up} / \mathrm{c}$ of $12 \mathrm{mg} / \mathrm{mg}$. (Figure $2 \mathrm{a}$ ) The relationships between $\mathrm{Up} / \mathrm{c}$ versus non-renal clearance of adalimumab demonstrated a direct linear relationship (slope $3.5 \pm 1.1$, intercept $-1.6 \pm 13.1, P=0.01$ ) (Figure 2b).

\section{Discussion}

The current study was conducted in order to understand the contributions of both renal and non-renal elimination routes toward the observation of increased total clearance of adalimumab, an antibody against $\mathrm{TNF} \alpha$, in patients with glomerular disease due to FSGS. ${ }^{17}$ We demonstrated total clearance values for adalimumab that were 2-fold higher after a single dose and up to 5-fold higher after multiple doses as compared to published data from patients with rheumatoid arthritis. ${ }^{17,19}$ The half-life for adalimumab was negatively related to the Up/c, suggesting that as the amount of proteinuria increased the half-life became shorter. ${ }^{17}$ In light of our unexpected previous findings and the lack of published reports evaluating the urinary excretion of therapeutic antibodies in patients with glomerular disease and heavy proteinuria, we assayed urine adalimumab concentrations to determine (1) the contribution of renal clearance to the enhanced total clearance in patients with FSGS and (2) the relationship between renal clearance and proteinuria.

Immunoglobulins are lost in the urine of nephrotic patients, but are normally not eliminated in healthy kidneys because of their large molecular weight. ${ }^{12}$ Loss of therapeutic immunoglobulin proteins through the kidneys

Table 2. Renal and Nonrenal Clearance of Adalimumab in Nephrotic Syndrome

\begin{tabular}{|c|c|c|c|c|c|c|c|c|}
\hline Patient ID & $\mathrm{AUC}(\mathrm{mcg} \mathrm{h} / \mathrm{L})$ & $\begin{array}{c}\text { Cumulative } \\
\text { amt. in urine at } \\
42 \text { hours } \\
\text { (mcg) }\end{array}$ & $\mathrm{CL}_{\text {total }}(\mathrm{mL} / \mathrm{hr})$ & $\mathrm{CL}_{\mathrm{R}}(\mathrm{mL} / \mathrm{hr})$ & $\mathrm{CL}_{\mathrm{NR}}(\mathrm{mL} / \mathrm{hr})$ & $\begin{array}{c}\text { Dose lost in } \\
\text { urine } \%\end{array}$ & $\mathrm{CL}_{\mathrm{R}} \%$ & $\mathrm{CL}_{\mathrm{NR}} \%$ \\
\hline \multicolumn{9}{|l|}{ Single dose } \\
\hline I & 960,744 & 736 & 33.3 & 0.8 & 32.5 & 2.3 & 2.3 & 97.7 \\
\hline 2 & 675,555 & $\mathrm{I}, 752$ & 59.2 & 2.6 & 56.6 & 4.4 & 4.4 & 95.6 \\
\hline 3 & 933,337 & 201 & 42.9 & 0.2 & 42.6 & $<1$ & 0.5 & 99.5 \\
\hline 4 & $127 \mid, 695$ & 156 & 15.7 & 0.1 & 15.6 & $<\mathrm{I}$ & 0.8 & 99.2 \\
\hline 5 & 2106,615 & 172 & 19.0 & 0.1 & 18.9 & $<\mathrm{I}$ & 0.4 & 99.6 \\
\hline 6 & $6|0,55|$ & 105 & 41.0 & 0.2 & 40.8 & $<\mathrm{I}$ & 0.4 & 99.6 \\
\hline Mean & 1093,083 & 520 & 35.2 & 0.7 & 34.5 & 1.8 & 1.5 & 98.5 \\
\hline St. Dev. & 549,427 & 647 & 16.2 & 1.0 & 15.5 & 1.4 & 1.6 & 1.6 \\
\hline \multicolumn{9}{|l|}{ Multi-dose } \\
\hline 2 & 282,069 & $\mathrm{I}, 794$ & $14 \mid .8$ & 6.4 & 135.5 & 4.5 & 4.5 & 95.5 \\
\hline $3^{a}$ & 828,951 & 860 & 48.3 & 1.0 & 47.2 & 2.1 & 2.2 & 97.8 \\
\hline 4 & 1466,865 & 59 & 13.6 & 0.0 & 13.6 & $<1$ & 0.1 & 99.9 \\
\hline 5 & 5000,434 & 145 & 8.0 & 0.0 & 8.0 & $<1$ & 0.4 & 99.6 \\
\hline 6 & $188 \mid, 984$ & 0 & 13.3 & 0.0 & 13.3 & $<\mathrm{I}$ & 0 & 100 \\
\hline 7 & 4368,529 & 45 & 9.2 & 0.0 & 9.2 & $<1$ & 0.1 & 99.9 \\
\hline Mean & 2124,090 & 998 & 37.8 & 1.6 & 36.2 & 3.3 & 2.9 & 97.1 \\
\hline St. Dev. & 1827,910 & 1,510 & 48.1 & 2.5 & 45.9 & 4.4 & 4.7 & 4.7 \\
\hline
\end{tabular}

$\mathrm{Cl}_{\mathrm{R}}$, renal clearance; $\mathrm{Cl}_{\mathrm{NR}}$, non-renal clearance; $\mathrm{Cl}_{\text {total }}$, total clearance.

${ }^{a}$ For patient 007-002 data is from week 12. Values < I were truncated to I for analysis of mean and standard deviation (SD). 


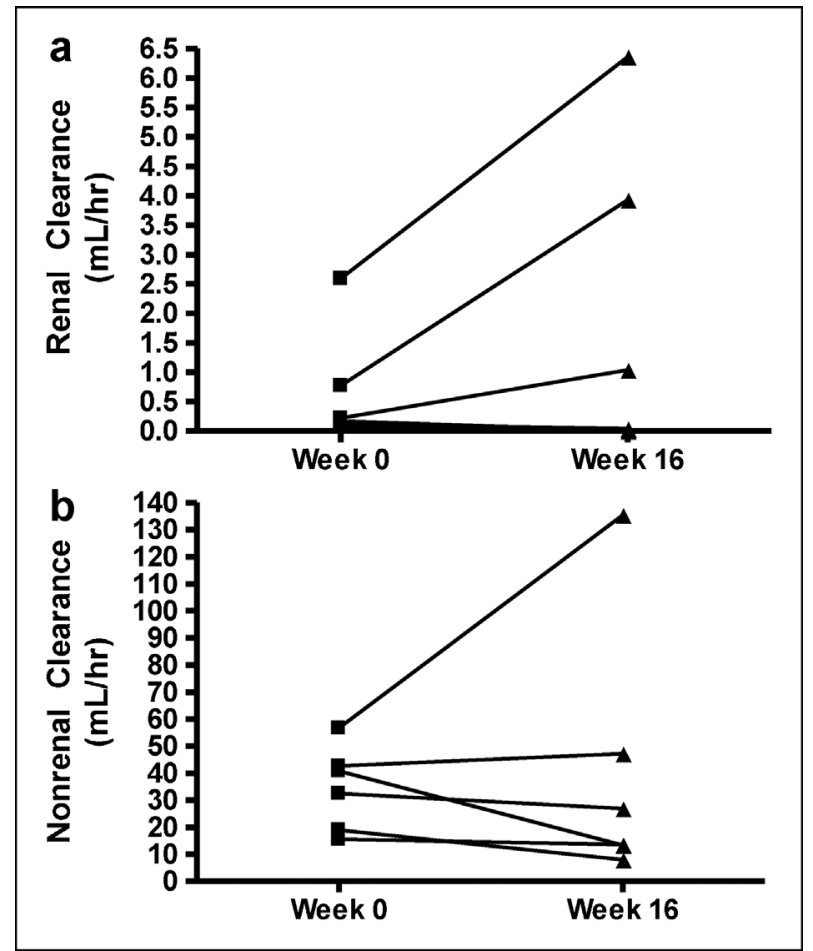

Figure I. Adalimumab renal clearance (a) and non-renal clearance (b) at weeks 0 and 16 for the six matched patients. The clearance of adalimumab at week 0 and week 16 demonstrated a non-significant increase in renal $(P=0.15)$ and non-renal $(P=0.70)$ values from study initiation until completion within patients.

in patients with glomerular disease could have consequences in terms of shorter drug half-lives, enhanced total clearance, and need for higher doses to achieve a therapeutic response. The current data showed $<1 \%$ to $13 \%$ of adalimumab was eliminated through the kidneys, suggesting the need for up to a $13 \%$ increase in dose to maintain targeted serum concentrations. The nonlinear regression analysis demonstrated an increase in $\mathrm{Cl}_{R}$ beginning at a $\mathrm{Up} / \mathrm{c}$ of $12 \mathrm{mg} / \mathrm{mg}$.

The neonatal Fc receptor is responsible for the recycling and clearance of $\mathrm{IgG}$ and contributes to the renal and non-renal clearance of therapeutic antibodies. ${ }^{20}$ The neonatal $\mathrm{Fc}$ receptor is present in liver, intestine, endothelial cells, placenta, skin, muscle, adipose, and kidney, ${ }^{21,22}$ and it has been documented to be upregulated in certain disease states. ${ }^{13,23}$ In the kidney, the neonatal Fc receptor is found on glomerular epithelial cells and on the apical membrane of proximal tubule epithelial cells. ${ }^{22}$ Functionally, it has been shown that the neonatal Fc receptor on kidney podocytes is used to clear IgG that can form immune complexes from the glomerular basement membrane. ${ }^{24}$ Decreased functionality of the receptor at the level of the podocyte could result in impaired $\mathrm{IgG}$ clearance from glomeruli and enhanced damage as reflected in proteinuria. ${ }^{24}$ Alternatively, altered expression

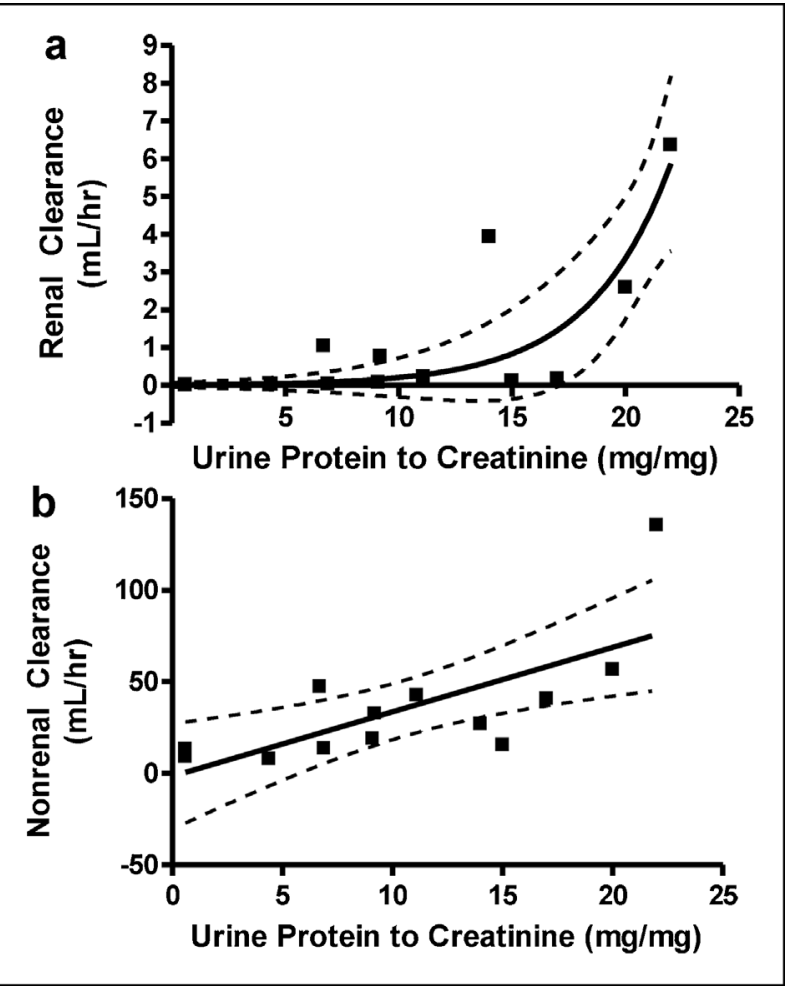

Figure 2. Regression of urine protein to creatinine ratio to adalimumab renal clearance $\left(\mathrm{Cl}_{R}\right)$ (a) and non-renal clearance $\left(\mathrm{Cl}_{N R}\right)$ (b). The relationships between urinary protein:creatinine (Up/c) excretion versus $\mathrm{Cl}_{\mathrm{R}}$ of adalimumab demonstrated a positive direction by nonlinear regression analysis (slope I.755 (C.I. -7.825 to I I.34), ED50 25.46 (C.I. - II3.0 to 163.9), $\left.R^{2} 0.7059\right)$. Nonlinear regression demonstrated an increase in $\mathrm{Cl}_{R}$ beginning at a $U_{p} / \mathrm{c}$ of $12 \mathrm{mg} / \mathrm{mg}$ (a). A positive relationship by linear regression analysis (slope $3.5 \pm \mathrm{I}$.I, intercept $-1.6 \pm 13.1, P=0.01$ ) was demonstrated for urine protein to creatinine ratio versus adalimumab $\mathrm{Cl}_{\mathrm{NR}}$ (b). Both graphs demonstrate the $95 \%$ confidence intervals.

of the neonatal $\mathrm{Fc}$ receptor in the proximal tubule may prevent tubular reabsorption of the filtered load of $\mathrm{IgG}$ and albumin. The relatively larger contribution of increased non-renal versus renal clearance to the increased adalimumab total clearance was demonstrated in this group of patients with FSGS. The linear regression analysis suggested that for every 1 unit increase in urinary protein excretion, the non-renal clearance would increase by $3.5 \mathrm{~mL} / \mathrm{hr}$. This clearance represents an 18 - fold greater contribution of non-renal versus renal clearance toward the increased total clearance. For a patient with a $\mathrm{Up} / \mathrm{c}$ of 10 , the non-renal clearance would be enhanced by $35 \mathrm{~mL} / \mathrm{min}$, roughly a third of the value for the total GFR. Various mechanisms are possible for the demonstrated increase in non-renal clearance. Increased catabolism of IgG based therapeutic antibodies through the neonatal $\mathrm{Fc}$ receptor pathway is one mechanism based on studies in patients with autoimmune diseases. ${ }^{13,14}$ However, it is not known how or if the functionality of the liver (metabolic) 
neonatal $\mathrm{Fc}$ receptor tracks with the kidney podocyte receptor. Enhanced function of the liver neonatal $\mathrm{Fc}$ receptor could contribute to increased non-renal clearance of adalimumab.

Production of antibodies to adalimumab is another plausible mechanism for increased clearance, although these were not assessed in this patient group. A recent study in patients with rheumatoid arthritis receiving adalimumab reported that $15 \%$ of patients had antiadalimumab antibodies after 16 weeks of therapy. ${ }^{25}$ However, the FSGS patients receiving adalimumab had total clearance values that were twofold higher than in rheumatoid arthritis patients at the time of the first dose, suggesting that anti-adalimumab antibodies were not responsible for this increase in non-renal clearance. A combined contribution of enhanced renal clearance, increased catabolism of adalimumab through the neonatal Fc receptor (enhanced non-renal clearance), and production of anti-adalimumab antibodies may account for the increased total clearance in FSGS patients.

While the results of the current study are novel and interesting, several study limitations are noted. Our current assessments only evaluated adalimumab as a therapeutic antibody. It is currently unknown whether the consistent findings would be observed with other therapeutic antibodies or other proteins. The current study also only included seven patients, necessitating a larger study to confirm the novel findings. Only nephrotic patients with FSGS receiving adalimumab were evaluated in the current study. The applicability of these results to patients with lower levels of proteinuria is not known. Future experimental plans include assessing additional biologic proteins and evaluating the mechanisms underlying the finding of enhanced nonrenal clearance.

\section{Conclusions}

Enhanced renal and non-renal clearance pathways contribute to the increased total clearance of adalimumab in patients with glomerular disease secondary to FSGS. Given the increased use of therapeutic proteins in patients with glomerular disease and nephrotic-range proteinuria, additional study on PK and pharmacodynamics in these patient populations is warranted. Since some therapeutic proteins are used off-label for the treatment of glomerular disease, the clinician should be aware of the need for dose adjustment in patients with significant proteinuria who are prescribed these biological agents. Further research is needed to discern the mechanisms for enhanced non-renal clearance of adalimumab in glomerulopathies such as FSGS. The results from the current research, which evaluated adalimumab, could be used to inform about the possibility of clearance alterations for other therapeutic proteins used to treat patients with proteinuric forms of kidney disease.

\section{Declaration of Conflicting Interest}

No conflict of interest.

\section{Funding}

This research was funded by the National Institutes of Health (NIH), National Institute of Diabetes and Digestive Diseases (NIDDK) grant 5R21-DK070341, the NIDDK intramural research program, and the General Clinical Research Centers program of the NIH National Center for Research Resources, via RR00046 (University of North Carolina at Chapel Hill) and RR018535 (North Shore-LIJ).

\section{References}

1. Stone JH, Merkel PA, Spiera R, et al. Rituximab versus cyclophosphamide for ANCA-associated vasculitis. $N$ Engl $J$ Med. 2010;363:221-232.

2. Lu TY, Ng KP, Cambridge G, et al. A retrospective seven-year analysis of the use of B cell depletion therapy in systemic lupus erythematosus at University College London Hospital: The first fifty patients. Arthritis Rheum. 2009;61:482-487.

3. Rovin BH, Furie R, Latinis K, et al. Efficacy and safety of rituximab in patients with active proliferative lupus nephritis: The lupus nephritis assessment with rituximab study. Arthritis Rheum. 2012;64:1215-1226.

4. Fervenza FC, Abraham RS, Erickson SB, et al. Rituximab therapy in idiopathic membranous nephropathy: a 2-year study. Clin J Am Soc Nephrol. 2010;5:2188-2198

5. Fervenza FC, Cosio FG, Erickson SB, et al. Rituximab treatment of idiopathic membranous nephropathy. Kidney Int. 2008;73:117125.

6. Ravani P, Magnasco A, Edefonti A, et al. Short-term effects of rituximab in children with steroid- and calcineurin-dependent nephrotic syndrome: A randomized controlled trial. Clin J Am Soc Nephrol. 2011;6:1308-1315

7. Ruggenenti $\mathrm{P}$, Cravedi $\mathrm{P}$, Sghirlanzoni $\mathrm{MC}$, et al. Effects of rituximab on morphofunctional abnormalities of membranous glomerulopathy. Clin J Am Soc Nephrol. 2008;3:1652-1659.

8. Lopez-Olivo MA, Kallen MA, Ortiz Z, Skidmore B, SuarezAlmazor ME. Quality appraisal of clinical practice guidelines and consensus statements on the use of biologic agents in rheumatoid arthritis: A systematic review. Arthritis Rheum. 2008;59:16251638.

9. Shah SB, Hanauer SB. Risks and benefits of the use of concomitant immunosuppressives and biologics in inflammatory bowel disease. Rev Gastroenterol Disord. 2008;8:159-168.

10. Aringer M, Graninger WB, Steiner G, Smolen JS. Safety and efficacy of tumor necrosis factor alpha blockade in systemic lupus erythematosus: An open-label study. Arthritis Rheum. 2004;50: 3161-3169.

11. Aringer M, Smolen JS. Efficacy and safety of TNF-blocker therapy in systemic lupus erythematosus. Expert Opin Drug Saf. 2008; 7:411-419

12. Ellis D, Buffone GJ. Protein clearances and selectivity determinations in childhood nephrosis: A reappraisal. Clin Chem. 1981;27: 1397-1400.

13. Zhou J, Pop LM, Ghetie V. Hypercatabolism of IgG in mice with lupus-like syndrome. Lupus. 2005;14:458-466.

14. Akilesh S, Petkova S, Sproule TJ, Shaffer DJ, Christianson GJ, Roopenian D. The MHC class I-like $\mathrm{Fc}$ receptor promotes humorally mediated autoimmune disease. J Clin Invest. 2004;113: $1328-1333$. 
15. McCarthy ET, Sharma R, Sharma M, et al. TNF-alpha increases albumin permeability of isolated rat glomeruli through the generation of superoxide. J Am Soc Nephrol. 1998;9:433-438.

16. Le Berre L, Herve C, Buzelin F, Usal C, Soulillou JP, Dantal J. Renal macrophage activation and Th2 polarization precedes the development of nephrotic syndrome in Buffalo/Mna rats. Kidney Int. 2005;68:2079-2090.

17. Joy MS, Gipson DS, Powell L, et al. Phase 1 trial of adalimumab in Focal Segmental Glomerulosclerosis (FSGS): II. Report of the FONT (novel therapies for resistant FSGS) study group. Am J Kidney Dis. 2010;55:50-60.

18. Trachtman H, Vento S, Gipson D, et al. Novel therapies for resistant focal segmental glomerulosclerosis (FONT) phase II clinical trial: study design. BMC Nephrol. 2011;12:8.

19. Weisman MH, Moreland LW, Furst DE, et al. Efficacy, pharmacokinetic, and safety assessment of adalimumab, a fully human antitumor necrosis factor-alpha monoclonal antibody, in adults with rheumatoid arthritis receiving concomitant methotrexate: A pilot study. Clin Ther. 2003;25:1700-1721.
20. Brambell FW, Hemmings WA, Morris IG. A theoretical model of gamma-globulin catabolism. Nature. 1964;203:1352-1354.

21. Ghetie V, Ward ES. Multiple roles for the major histocompatibility complex class I-related receptor FcRn. Аnпи Rev Immunol. 2000; 18:739-766.

22. Haymann JP, Levraud JP, Bouet S, et al. Characterization and localization of the neonatal $\mathrm{Fc}$ receptor in adult human kidney. $\mathrm{J} \mathrm{Am}$ Soc Nephrol. 2000;11:632-639.

23. Christianson GJ, Brooks W, Vekasi S, et al. Beta 2-microglobulindeficient mice are protected from hypergammaglobulinemia and have defective antibody responses because of increased $\mathrm{IgG}$ catabolism. J Immunol. 1997;159:4781-4792.

24. Akilesh S, Huber TB, Wu H, et al. Podocytes use FcRn to clear IgG from the glomerular basement membrane. Proc Natl Acad Sci USA. 2008;105:967-972.

25. Bartelds GM, Krieckaert CL, Nurmohamed MT, et al. Development of antidrug antibodies against adalimumab, association with disease activity, treatment failure during long-term follow-up. JAMA. 2011; 305:1460-1468. 